\title{
Heat transfer, physiological responses, and subjective perceptions during short contact time with wood or other materials
}

\author{
Yuko Tsunetsugu ${ }^{1 *}$ and Masaki Sugiyama
}

\begin{abstract}
This study investigates the physiological responses and subjective perceptions of touching wood. In particular, it focuses on their respective relationships with the amount of heat transfer across the hand-material interface during contact. The study participants included 55 university students ( 20 females and 35 males) who gave written informed consent. The participants' blood pressure, pulse rate, and cerebral blood hemoglobin concentrations were measured continuously for $90 \mathrm{~s}$ while they gently held vertical bar-shaped specimens of Japanese cypress (Chamaecyparis obtusa), Japanese oak (Quercus crispula), polyethylene, and aluminum. The specimens also included wood with a surface coating. We measured subjective warmth and comfort as well as the heat flux between the palm and the surface of the material. The wooden materials were rated as significantly warmer compared to aluminum and polyethylene, regardless of the wood species (cypress or oak) or its coating; this result corresponds with smaller heat transfers in the wooden materials. Additionally, the wooden materials were more comfortable to hold as compared to the aluminum bar. Based on the changes in blood pressure, touching Japanese cypress and uncoated Japanese oak were interpreted to induce less physiological stress. Therefore, we can conclude that wood, with lower thermal conductivity, feels warm, and it causes relatively smaller physiological changes compared to other materials with higher thermal conductivity. Thus, they may present less physiological burdens when touched.
\end{abstract}

Keywords: Tactile sensation, Thermal conductivity, Near-infrared spectroscopy, Finapres method

\section{Introduction}

Wood is a common material. It is a major raw and finishing material for furniture, flooring, handrails, and countertops. People have countless opportunities to come into contact with wood in their everyday lives.

Previous studies have connected several physical properties of wood to perceptions of warmth/coldness, roughness/smoothness, and softness/hardness. The perception of warmth/coldness has been reported to be highly related to the thermal conductivity of the touched material as well as the heat flow rate across the

\footnotetext{
*Correspondence: a-yukot@g.ecc.u-tokyo.ac.jp

1 Department of Biomaterial Sciences, Graduate School of Agricultural and Life Sciences, The University of Tokyo, 1-1-1 Yayoi, Bunkyo-ku, Tokyo 113-8657, Japan

Full list of author information is available at the end of the article
}

hand-material interface [1]. Subjective tactile roughness was found to be affected by the deviation of the peak heights of the surface roughness profile of wood, but not the centerline mean roughness [2]. Perceived tactile hardness is strongly related to physical hardness and is modified by warmth and roughness perceptions [3]. Each study demonstrated that the subjective sensations were correlated with the logarithm of the respective physical and thermal properties, which is in accordance with the Weber-Fechner law.

The recent development of instruments has enabled a more precise assessment of the physiological effects of touching wooden materials. An early study investigated changes in the blood pressure and pulse rate of 19 young female participants when they touched sugi (Cryptomeria japonica), hinoki (Chamaecyparis obtusa), silk,
Springer Open (c) The Author(s) 2021. This article is licensed under a Creative Commons Attribution 4.0 International License, which permits use, sharing, adaptation, distribution and reproduction in any medium or format, as long as you give appropriate credit to the original author(s) and the source, provide a link to the Creative Commons licence, and indicate if changes were made. The images or other third party material in this article are included in the article's Creative Commons licence, unless indicated otherwise in a credit line to the material. If material is not included in the article's Creative Commons licence and your intended use is not permitted by statutory regulation or exceeds the permitted use, you will need to obtain permission directly from the copyright holder. To view a copy of this licence, visit http://creativeco mmons.org/licenses/by/4.0/. 
denim, stainless steel, and a vinyl bag containing cold water at $6{ }^{\circ} \mathrm{C}$ [4]. Systolic blood pressure and pulse rate showed a larger increase in response to stainless steel and the bag filled with cold water than sugi, hinoki, and silk. The smaller physiological changes were interpreted as suggesting that wood and silk caused less stress to the participants. Another study focused on the effect of the material and temperature of the touched specimens [5]. In this study, 13 young male participants underwent 60-s contact with sugi, hinoki, oak (Quercus crispula), acrylic plastic, and aluminum at $20{ }^{\circ} \mathrm{C}$, and oak and acrylic plastic at $5{ }^{\circ} \mathrm{C}$. Sugi, hinoki, and oak induced a slight change in systolic blood pressure, except for a transient increase immediately after contact. Contact with the cooled acrylic plastic plate significantly increased systolic blood pressure, while the cooled oak plate did not. It was concluded that touching wood caused less physiological stress, regardless of the specimen's temperature, compared to the "artificial" materials.

A recent study measured changes in the brain and autonomic nervous activities of 22 female university students when they came in contact with hinoki and marble [6]. Contact with hinoki caused a larger decrease in regional brain activity than did marble, as assessed using nearinfrared spectroscopy. Touching hinoki also increased parasympathetic nervous activity while marble did not cause a significant change. The same research group investigated the effects of different surface coatings with the same physiological measurements [7]. In this study, 18 female university students touched white oak panels with five different surface finishes. The results showed that an uncoated white oak panel decreased brain activity while the urethane-coated and mirror-finished (pianolike) panels increased it. The parasympathetic nervous activity showed a greater enhancement when participants touched the uncoated wood than when they touched the urethane and mirror-finished wood. These results were explained to reveal that touching uncoated wood could result in a "physiological relaxation effect".

In summary, previous physiological studies demonstrated that contact with wood (hinoki, sugi, oak, and white oak) may induce less physiological stress than contact with steel, acrylic plastic, or marble, and thick surface coatings may attenuate the results. However, the factors that induce these differences are unclear, as both the physical properties of touched materials and psychological perceptions may affect physiological responses. No study has investigated the differences between hardwood and softwood or among respondents. This information could prove very useful for designers and suppliers of wooden interiors and products. Therefore, we aimed to investigate the relationships between heat transfer, subjective perceptions, and impressions
Table 1 Specimen details

\begin{tabular}{|c|c|c|}
\hline Notation & Species/material & Surface treatment \\
\hline $\mathrm{HU}$ & \multirow{2}{*}{$\begin{array}{l}\text { Japanese cypress } \\
\text { (hinoki) } \\
\text { (Chamaecyparis } \\
\text { obtusa) }\end{array}$} & Sandpaper (P240) polishing \\
\hline $\mathrm{HC}$ & & $\begin{array}{l}\text { Sandpaper (P240) polishing + urethane } \\
\text { coating }^{\mathrm{a}}\end{array}$ \\
\hline OU & \multirow{2}{*}{$\begin{array}{l}\text { Japanese oak } \\
\text { (mizunara) } \\
\text { (Quercus } \\
\text { crispula) }\end{array}$} & Sandpaper (P150) polishing \\
\hline OC & & Sandpaper (P150) + urethane coating ${ }^{a}$ \\
\hline PE & Polyethylene & Sandpaper polishing \\
\hline $\mathrm{AL}$ & Aluminum & Hairline finishing \\
\hline
\end{tabular}

a Undercoat: US-40-P, topcoat: UF-15-70P (GEN GEN CORPORATION, Japan)

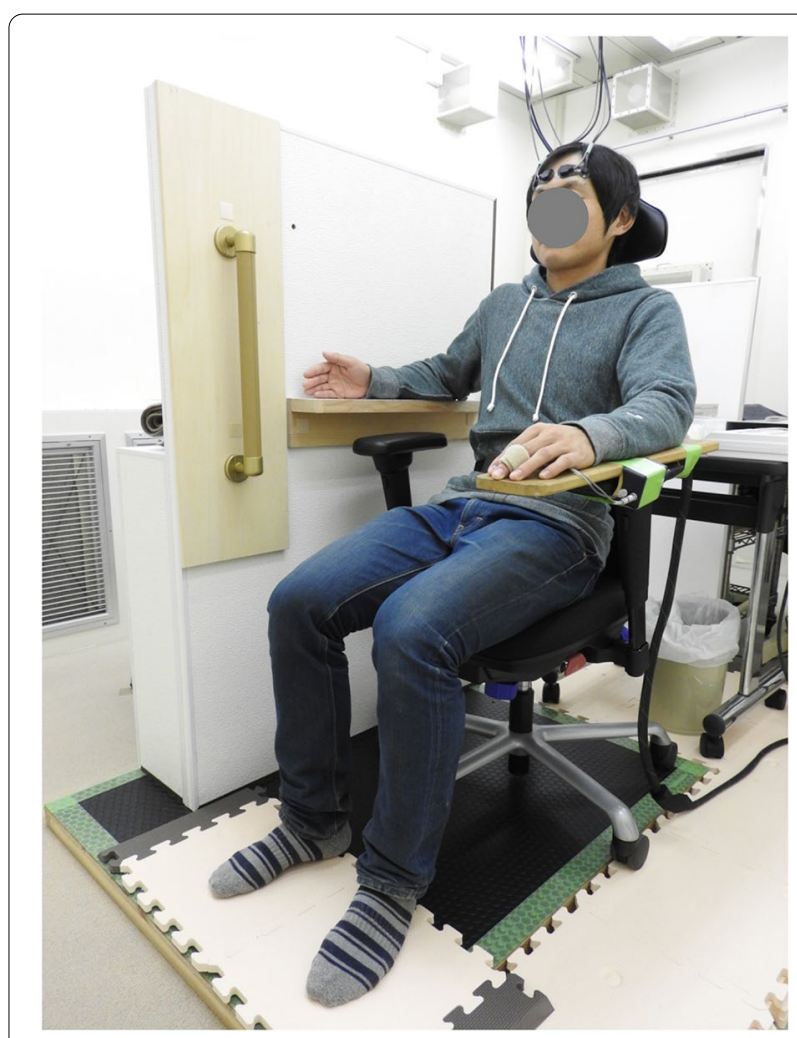

Fig. 1 Setting of the experiment

of touched materials, and male and female respondents' physiological changes when touching different materials, including hardwood and softwood.

\section{Materials and methods Specimens}

Six bar-shaped materials $(d=32 \mathrm{~mm}, L=400 \mathrm{~mm})$ were prepared (Table 1). Each specimen was presented to the participants as a vertical grab bar using a mockup setting of a wall and armrest (Fig. 1). The round-bar shape 
of the specimens was chosen based on a preliminary investigation in which we compared flat-board- and round-bar-shaped specimens. Our results revealed that a round-bar-shaped specimen showed a larger contact area between the hand (fingers and palm) and the material than those of flat-board-shaped specimens, and without applying the force needed to stretch the fingers for full hand contact in flat-board-shaped specimens. Therefore, the rounded-bar-shaped specimen minimizes the individual differences in the contact area between the hand and the materials. Additionally, we confirmed a more stable measurement of the heat flux between the hand and the material for the round-bar-shaped specimen.

A commercially available grab bar $(d=32 \mathrm{~mm})$ that was made of an aluminum alloy pipe core covered with silicone elastomer was prepared for a practice session. All specimens were kept in a room controlled at $24{ }^{\circ} \mathrm{C}$ and $50 \% \mathrm{RH}$ throughout the experimental period. The surface temperature of the specimens was measured at the beginning of each experimental day.

\section{Participants}

The experiment was conducted with 18 male participants in November 2015, 20 female participants in July 2016, and 17 male participants in July and August 2017. In total, 20 females $(22.1 \pm 1.96$ years old) and 35 males $(22.0 \pm 1.74$ years old) participated in the study. Before proceeding with the measurements, we informed the participants about the aim and procedure of the experiment and obtained their written informed consent. This study was approved by the Ethical Review Committee of the Forestry and Forest Products Research Institute, Japan.

\section{Measurements and procedure}

The measurements were conducted individually in an artificial climate chamber controlled at $24{ }^{\circ} \mathrm{C}$ and $50 \%$ $\mathrm{RH}$. First, the participants sat comfortably on a chair with their eyes closed and their right arm placed on the armrest. The surface temperature of the palm was measured using an infrared thermometer. After $60 \mathrm{~s}$, they were instructed to move their right arm forward and hold the presented bar (specimen) while keeping their eyes closed. After $90 \mathrm{~s}$, the experimenter instructed the participants to return their right arm to the original position, covered the specimen with a cloth, and then instructed the participants to open their eyes. The participants' blood pressure, pulse rate, and hemoglobin concentration of the right and left prefrontal areas were measured continuously every second during the rest period $(60 \mathrm{~s})$ and tactile (90 s) session. After opening their eyes, the participants were told to rate their tactile perceptions and impressions of the bar using visual analog scale (VAS).
The rating was performed without showing the target material to the participants by covering it with a cloth, as mentioned above. This procedure was repeated seven times, including a practice session.

The physiological indices were selected based on previous studies [4-6]. The participants wore a cuff on their left middle fingers to measure systolic blood pressure (SBP), diastolic blood pressure (DBP), and pulse rate (PR) (Finometer PRO, Finapres Medical Systems, the Netherlands). Changes in brain activity were monitored by measuring the cerebral oxygenated and deoxygenated hemoglobin concentrations (OXY and DEOXY) every second from above the forehead using a 2-channel nearinfrared spectroscopy (NIRS) system (NIRO-200, Hamamatsu Photonics K.K., Japan). The subjective ratings using the VAS consisted of 12 items, of which 2 (warm/ cold and comfortable/uncomfortable) were analyzed in this study.

Because we used round-bar-shaped specimens, detailed instructions were given regarding how to hold the bars prior to the measurement. The participants were instructed not to touch or firmly grasp, but naturally hold the bars by using their entire hand for $90 \mathrm{~s}$ without moving the hand. All participants practiced the procedure with the commercially available bar first and then experienced the six grab bars in randomized order.

The heat flux between the hand and the specimens was measured in the 17 males who participated in the study in 2017. This measurement was conducted separately after the abovementioned physiological measurement, with an interval of more than $2 \mathrm{~h}$. Each participant touched the six grab bars in the same way as in the physiological session, but with their eyes open. A heat flow sensor (Z2013, HIOKI E.E. CORPORATION Japan, sensor dimension: $10 \mathrm{~mm} * 31.6 \mathrm{~mm} * 0.25 \mathrm{~mm}$ thickness) was attached to the surface of each bar with double-sided tape, which has low thermal conductivity. We instructed the participants to place their hands where the sensor touched the base region of the fingers (palmar monticuli). The heat flux was measured at a rate of $100 \mathrm{~Hz}$ while the participants grabbed each bar over the sensor for $90 \mathrm{~s}$.

\section{Data analysis}

Regarding the physiological indices (SBP, DBP, PR, OXY, and DEOXY), the average value for over $30 \mathrm{~s}$ before touching each bar was considered the baseline, and it was subtracted from the data during the tactile period to calculate the relative changes. Thereafter, the average values were calculated for every second to examine the timecourse change. Since the changes in hemoglobin concentrations determined in the left and right prefrontal areas showed similar time-course changes, the data on the left side will be reported hereafter. 
To examine the effects of material and gender on the physiological indices, we calculated the average of the relative changes in the physiological indices for over 90 s during the tactile period. Since all the physiological indices exhibited significant changes during the first $30 \mathrm{~s}$ of contact, the mean, maximum, and minimum values for this period were also calculated and included in the statistical analysis. The subjective VAS ratings were converted to scores ranging from -5 to +5 , setting the neutral point to 0 . A two-way ANOVA with material (six levels) and gender (two levels) as the main factors was conducted. Using a paired t-test or Wilcoxon signed-rank test with Holm correction, multiple comparisons were performed when the main effect was significant.

The heat flux data was not obtained from one of the 17 participants because of a technical problem. We calculated the amount of heat transfer $\left(\mathrm{kJ} / \mathrm{m}^{2}\right)$ by integrating the heat flux for the $90 \mathrm{~s}$ of contact. The average of the total amount of heat transfer for each material was compared using one-way repeated ANOVA and post hoc test using the Holm correction.

To explore the relationships among the heat transfer, subjective ratings, and physiological responses, the correlations between the following parameters were investigated: the amount of heat transfer; scores for comfortable and warm feelings, mean, maximum, and minimum values of the physiological indices during the first $30 \mathrm{~s}$ of contact with the bars. The amount of heat transfer for the participants who were not involved in the actual measurement of heat flux was estimated as follows: first, the regression equations between the heat transfer and temperature difference between the palm and the specimens were computed for each material setting the y-intercept to 0 using the measured data of 16 participants. Thereafter, the heat transfer for each participant was calculated by interpolating the temperature differences into the regression equations.

All statistical analyses were performed using the IBM SPSS Statistics 25 software (IBM Corp. Armonk, USA), and a $p$-value $<0.05$ was considered statistically significant.

\section{Results}

Surface temperature of the specimens and the amount of heat transfer at the interface between the palm and the grab bars

The surface temperature of the specimens, measured at the beginning of each experimental day, were $24.2 \pm 0.708{ }^{\circ} \mathrm{C}(\mathrm{HU}), 24.1 \pm 0.683{ }^{\circ} \mathrm{C}(\mathrm{HC}), 24.2 \pm 0.669$ ${ }^{\circ} \mathrm{C}(\mathrm{OU}), 24.1 \pm 0.636{ }^{\circ} \mathrm{C}(\mathrm{OC}), 24.0 \pm 0.638^{\circ} \mathrm{C}(\mathrm{PE})$, and $24.4 \pm 0.699{ }^{\circ} \mathrm{C}(\mathrm{AL})($ mean $\pm \mathrm{SD})$. No significant differences in the surface temperature of the six materials were observed.
The material factor was significant $(p<0.01)$ for the amount of heat transfer. The amount of heat transfer when touching AL was larger compared to when touching any other material. Moreover, that of PE was larger than that of any of the wooden materials. In addition, the amount of heat transfer when touching $\mathrm{OU}$ and $\mathrm{OC}$ was larger than when touching $\mathrm{HU}$ and $\mathrm{HC}$, irrespective of the surface coating (Fig. 2).

\section{Time-course changes in blood pressure, pulse rate,} and hemoglobin concentration in the prefrontal area The changes in SBP, DBP, and PR over time for the six tested materials were similar (Figs. 3 and 4). When the participants touched the materials (at $0 \mathrm{~s}$ in the graphs), their SBP and DBP rapidly rose, dropped, and then increased significantly over time. SBP showed higher maximum and minimum values compared to DBP. Additionally, PR showed a rapid increase and subsequent decrease; however, unlike blood pressure, it remained lower than the baseline value.

Both OXY and DEOXY showed a very steep decrease upon contact, and only OXY recovered later (Fig. 5).

\section{Influence of material and gender on physiological responses}

The main effect of material was significant for the mean and the minimum SBP of the first $30 \mathrm{~s}$ after touching the materials $(p<0.05$ for both). The post hoc test revealed that the mean SBP during this period was higher in AL than in $\mathrm{HU}$, and the minimum value was higher in $\mathrm{AL}$ than in HU, HC, and OU (Fig. 6a and b). The main effects of material and gender were significant to the maximum

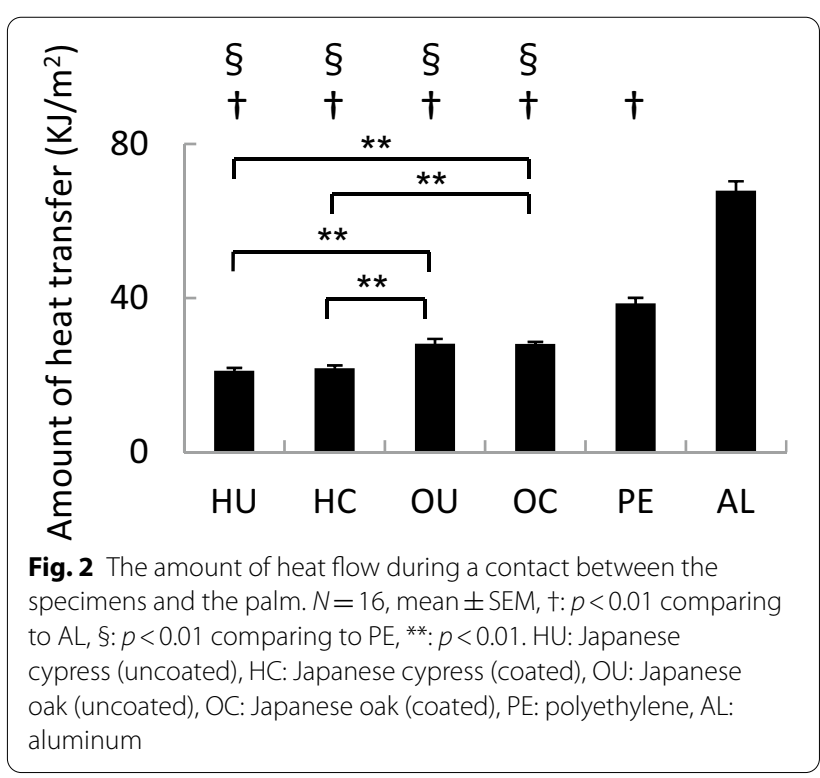




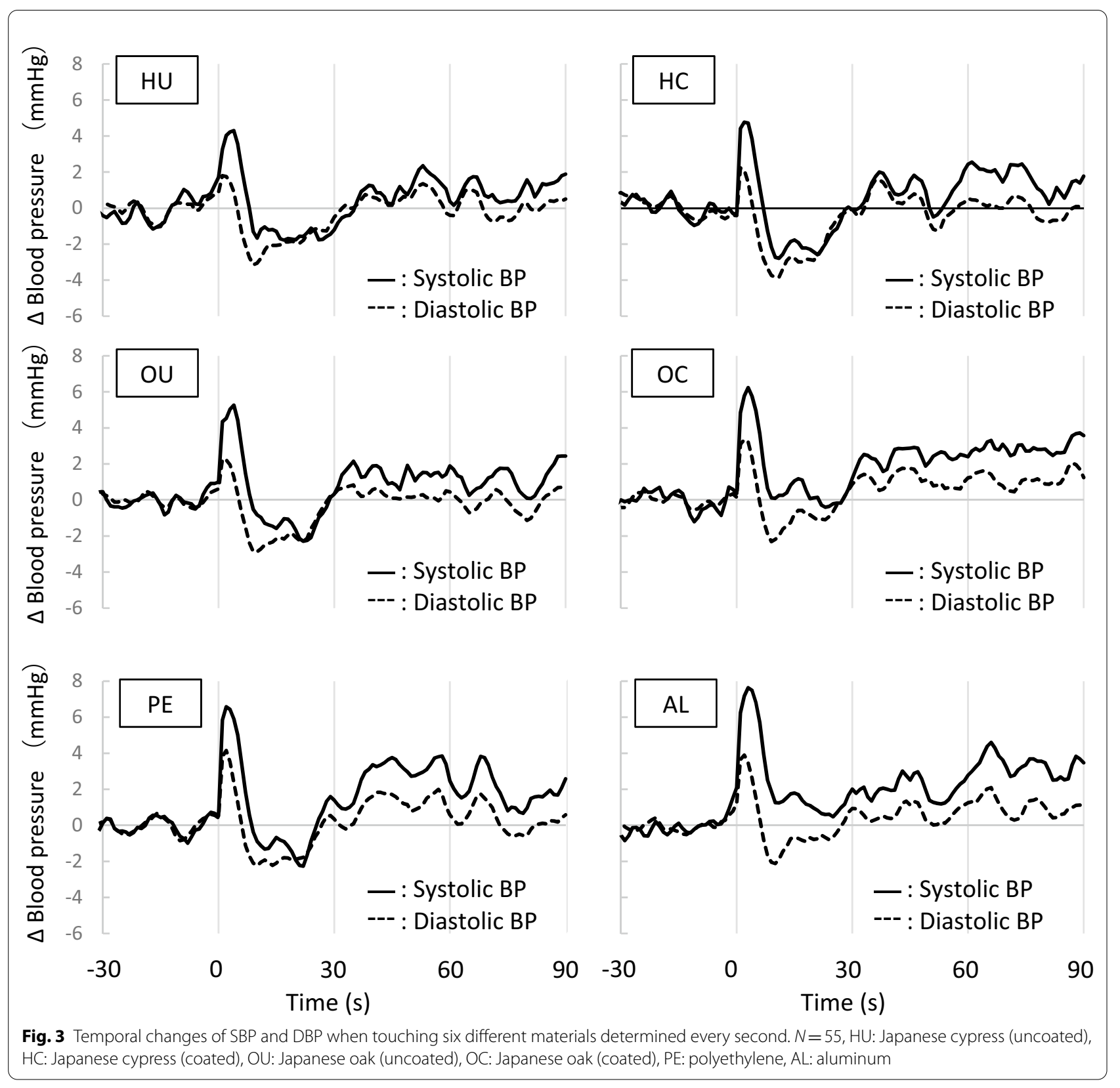

PR during the first $30 \mathrm{~s}$ ( $p<0.05$ for both). The maximum PR was significantly higher in PE than in AL, and the female participants exhibited a significantly lower maximum PR compared to the male participants (Fig. 6c). No significant effect of material, gender, or interaction between material and gender was found for the other parameters examined.

\section{Subjective ratings}

The material factor was significant $(p<0.01)$ for the impression of "warmth." AL was found to be significantly colder than any other material, and PE was colder compared to any of the wooden materials. $\mathrm{HU}$ was evaluated to be significantly warmer than $\mathrm{OU}$ and $\mathrm{OC}$. The gender factor and the interaction between material and gender were not significant (Fig. 7a).

As for the impression of "comfort," the main effect of the material was significant $(p<0.01)$. AL was evaluated to be significantly less comfortable compared to the other materials, except for OU. The main effect of gender was also significant $(p<0.05)$ : the female 


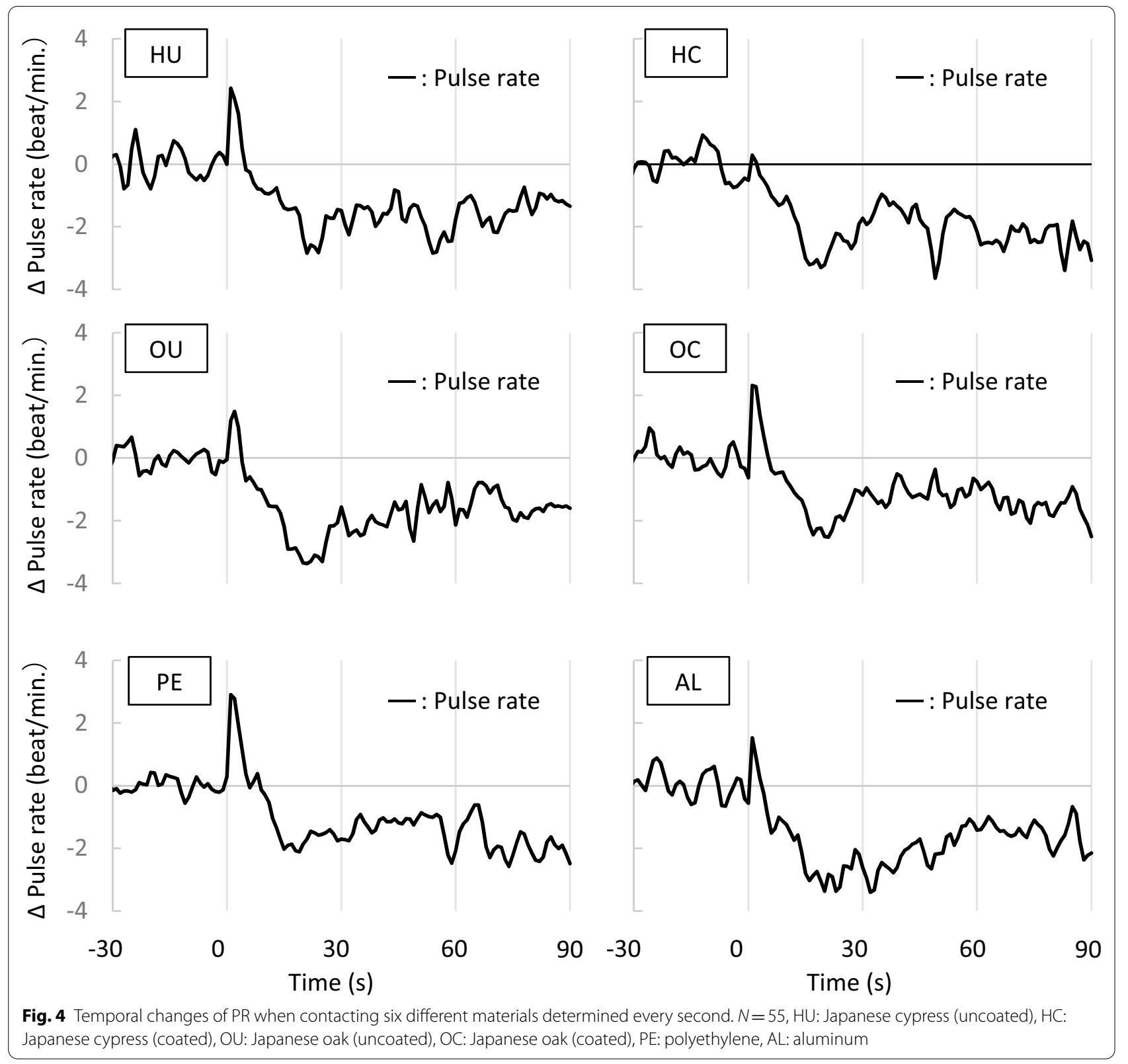

participants rated the materials significantly more comfortable compared to the male participants (Fig. 7b).

\section{Correlations between heat transfer, subjective perceptions,} and physiological responses

Table 2 summarizes the correlation coefficients between the amount of heat transfer, subjective warm and comfortable perceptions, mean, maximum, and minimum values of blood pressure and pulse rate for the first $30 \mathrm{~s}$ of contact. The amount of heat transfer was significantly correlated with comfortable and warm feelings as well as the mean and minimum SBP, and the mean of DBP. The perceptions of warmth and comfort showed a significant positive correlation with each other, and both feelings had negative correlations with the mean or minimum SBP, DBP, and PR. OXY and DEOXY showed no significant correlations with heat transfer and subjective perceptions; thus, they are not included in the table.

\section{Correlations among the physiological indices}

Table 3 summarizes the correlation coefficients among the mean of each physiological index over the first $30 \mathrm{~s}$ of contact. SBP, DBP, and PR exhibited significant positive correlations with each other, with a weaker correlation 


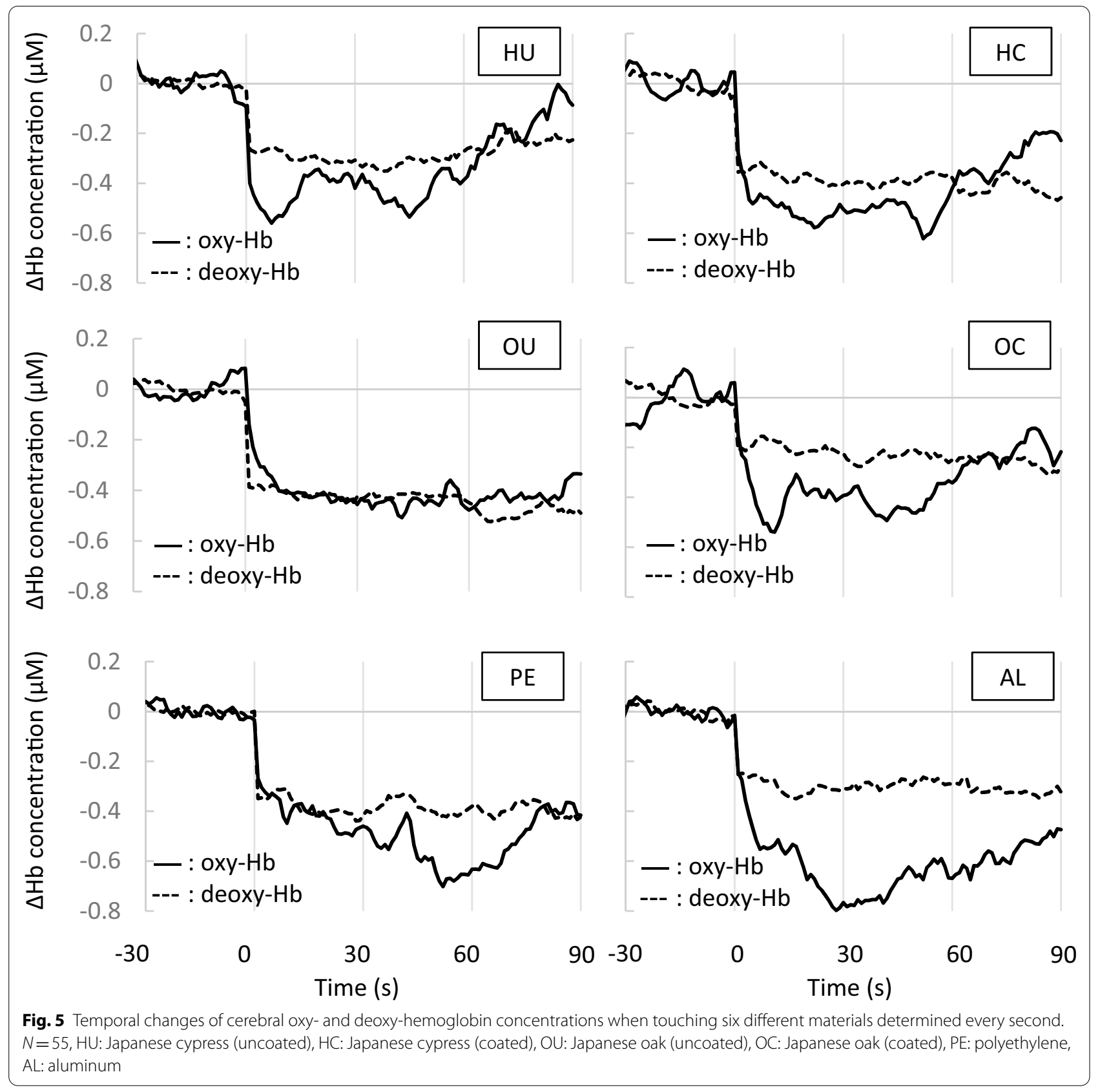

between blood pressure and PR than between the two blood pressure indices. Additionally, the means of OXYand DEOXY were positively correlated with SBP and DBP. DEOXY showed a positive correlation with the PR, whereas it exhibited no correlation with OXY.

\section{Discussion}

We investigated the physiological and psychological responses to touching wood and other materials in young male and female participants to compare wood/ non-wood, hardwood/softwood, and coated/uncoated wood. We compared the relationships between heat transfer, psychological responses, and physiological changes, as well as the potential differences between the male and female respondents. Through a preliminary investigation, a round-shaped bar was chosen as specimen to ensure that the entire hand was in contact with the material. Consequently, the participants were instructed to hold the specimens instead of only touching them, as in previous studies. 


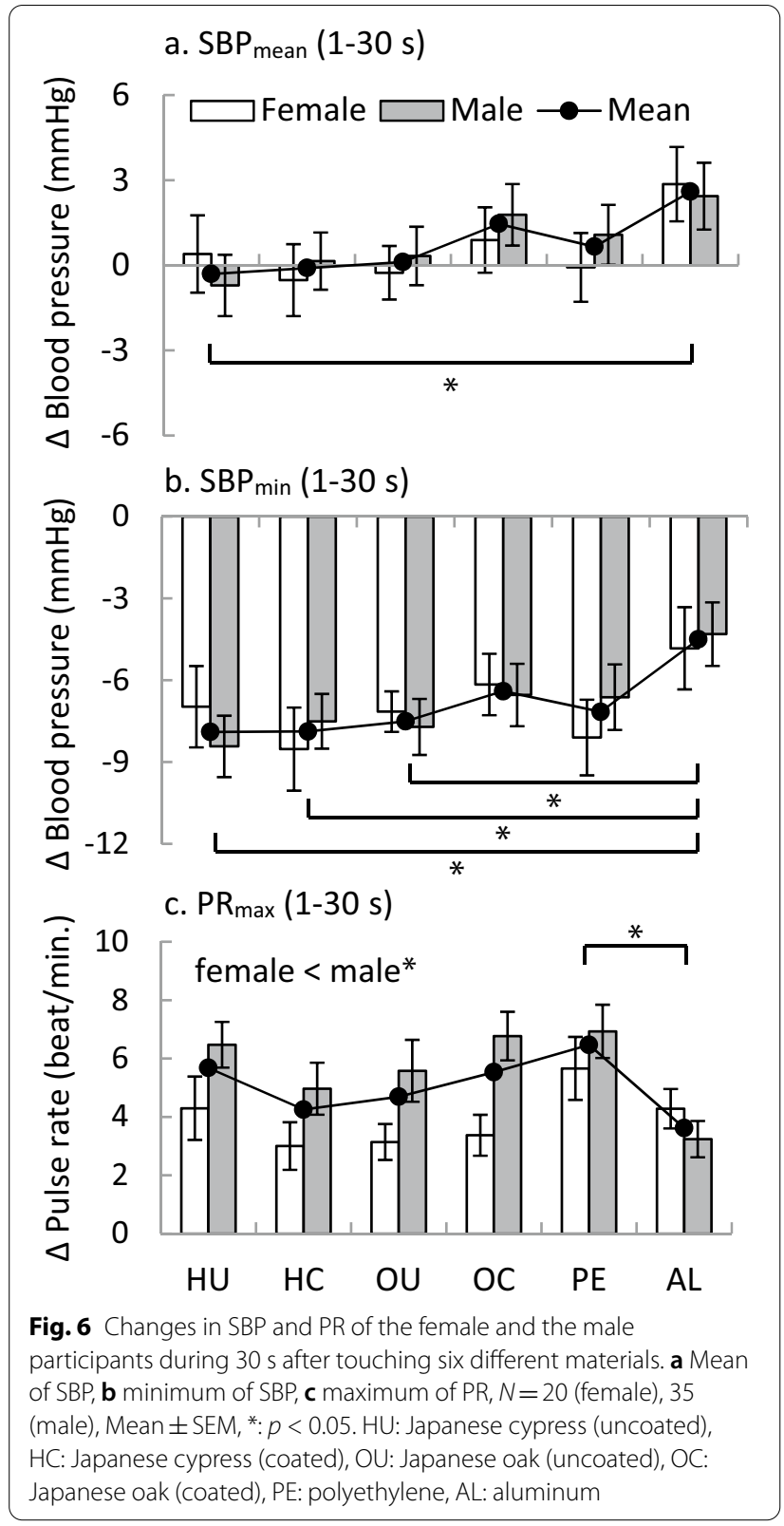

The overall trend in changes in physiological indices over time was similar among the six materials. Blood pressure and pulse rate exhibited an initial increase and a subsequent decrease, and then the blood pressure gradually recovered or increased whereas the pulse rate remained below the baseline. Increased blood pressure and decreased pulse rate induced by local or whole-body cooling have been well documented by various previous studies, including those related to the so-called hunting reaction [8]. One study reported that immersing a hand in water at $5{ }^{\circ} \mathrm{C}$ increased the systolic blood pressure by $10-15 \mathrm{mmHg}$, and it caused an initial increase
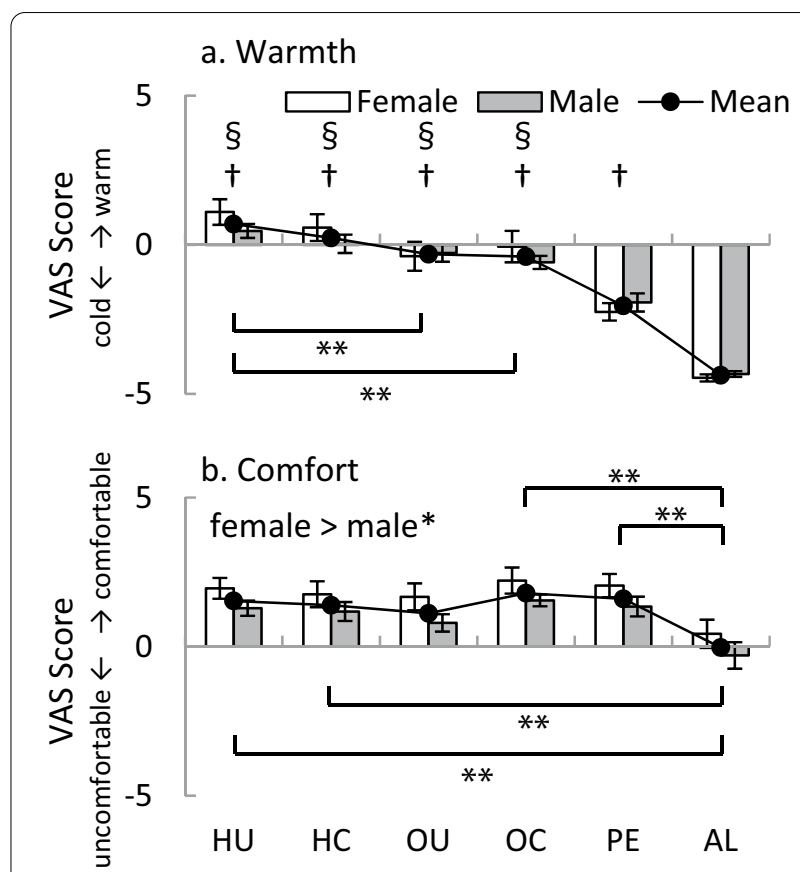

Fig. 7 Scores of "warm-cold" and "comfortable-uncomfortable" perceptions of the female and the male participants when touching six different materials. a Warm-cold, $\mathbf{b}$ comfortable-uncomfortable, $N=20$ (female), 35 (male), mean \pm SEM, $+: p<0.01$ comparing to $\mathrm{AL}, \S: p<0.01$ comparing to $\mathrm{PE},{ }^{*}: p<0.05,{ }^{*}: p<0.01$. HU: Japanese cypress (uncoated), HC: Japanese cypress (coated), OU: Japanese oak (uncoated), OC: Japanese oak (coated), PE: polyethylene, AL: aluminum

and a subsequent decrease in heart rate within $2 \mathrm{~min}$ in male and female participants [9]. These results were supported by various studies that demonstrated timedependent blood pressure and heart rate changes during hand immersion in water at $5{ }^{\circ} \mathrm{C}$ or $2{ }^{\circ} \mathrm{C}[10,11]$. As previously explained, we assume that the initial rise in blood pressure and pulse rate upon contact in this study could be attributed to a sympathetic activation triggered by the cold sensation owing to the temperature difference between the palm (approximately $37^{\circ} \mathrm{C}$ ) and the grab bars (approximately $25^{\circ} \mathrm{C}$ ) [11, 12]. The subsequent drop in the pulse rate may be mainly caused by baroreflex to compensate for the rise in blood pressure [13], although other factors such as a parallel activation of both sympathetic and parasympathetic nervous systems may also be responsible [12].

The simultaneous decrease in oxy- and deoxy-hemoglobin concentrations upon contact in this study can be because of the decrease in the blood volume in the measured area [14]. Cerebral blood flow is maintained via autoregulation, which is a process for maintaining adequate and stable blood flow while arterial pressure changes [15]. A recent study suggested that cerebral 
Table 2 Correlation coefficients between the heat transfer, VAS scores, blood pressure, and pulse rate

\begin{tabular}{|c|c|c|c|c|c|c|c|c|c|c|c|}
\hline & \multirow[t]{2}{*}{ Warmth } & \multirow[t]{2}{*}{ Comfort } & \multicolumn{3}{|l|}{ SBP } & \multicolumn{3}{|l|}{ DBP } & \multicolumn{3}{|l|}{ PR } \\
\hline & & & Mean & Max & Min & Mean & Max & Min & Mean & Max & Min \\
\hline Heat transfer & $-0.69^{* *}$ & $-0.26^{* *}$ & $0.13^{*}$ & 0.08 & $0.14^{*}$ & $0.12^{*}$ & 0.04 & 0.08 & -0.04 & -0.07 & -0.02 \\
\hline Warmth & & $0.27^{* *}$ & $-0.18^{* *}$ & -0.10 & $-0.21^{* *}$ & $-0.12^{*}$ & -0.08 & $-0.14^{* *}$ & 0.07 & 0.10 & 0.01 \\
\hline Comfort & & & $-0.14^{*}$ & -0.05 & $-0.14^{*}$ & -0.07 & -0.02 & $-0.13^{*}$ & 0.06 & 0.02 & $0.12^{*}$ \\
\hline
\end{tabular}

$N=323-330,{ }^{*}: p<0.05,{ }^{* *}: p<0.01$, SBP: systolic blood pressure, DBP: diastolic blood pressure, PR: pulse rate, mean, max, and min: the mean, maximum, and minimum during the first $30 \mathrm{~s}$ of contact

Table 3 Correlation coefficients among the means of blood pressure, pulse rate, and hemoglobin concentrations

\begin{tabular}{lllll}
\hline & DBP & PR & OXY & DEOXY \\
\hline SBP & $0.59^{* *}$ & $0.15^{* *}$ & $0.20^{* *}$ & $0.15^{* *}$ \\
DBP & & $0.26^{* *}$ & $0.12^{* *}$ & $0.16^{* *}$ \\
PR & & 0.08 & $0.19^{* *}$ \\
OXY & & & & 0.00
\end{tabular}

$N=330, * *: p<0.01$, SBP: systolic blood pressure, DBP: diastolic blood pressure, PR: pulse rate,

OXY: oxy-hemoglobin concentration, DEOXY: deoxy-hemoglobin concentration, mean: the mean during the first $30 \mathrm{~s}$ of contact

autoregulation is achieved up to $62 \%$ by three different physiological mechanisms, that is, sympathetic, cholinergic (parasympathetic), and myogenic components combined. Generally, neurogenic (sympathetic and parasympathetic) components cause vasoconstriction in counteracting a rise in arterial pressure. In addition, cerebral autoregulation has been reported to be effective for a slower change in blood pressure $(>30 \mathrm{~s})$, whereas it is less so during faster changes $[16,17]$. Based on the previous findings, the changes in cerebral blood flow in this study may be explained as follows: the fastest parasympathetic and the subsequent sympathetic reflexes counteracted the fast increase in blood pressure, thus resulting in vasoconstriction that was reflected in the decreased oxy- and deoxy-hemoglobin signals of the NIRS. The following increase in oxy-hemoglobin concentration can be attributed to autoregulation becoming effective in a delayed manner.

Although speculative, the above interpretations of the physiological mechanism underlying the time-course responses are partly supported by the correlation analysis. We demonstrated that the heat transfer and the subjective warmth exhibited a significant correlation with blood pressure, but not with the pulse rate and brain hemoglobin concentrations. On the other hand, the pulse rate and brain hemoglobin concentrations significantly correlated with blood pressure. These relations support the interpretation that emphasizes the effect of physiological reflex responses on changes of the blood pressure, pulse rate and brain blood flow. The relation to perceived comfort was not negligible in blood pressure and pulse rate but it was less dominant in the brain blood flow in the results in this study.

The smaller change in SBP during the first $30 \mathrm{~s}$ when contacting coated and uncoated Japanese cypress and uncoated Japanese oak indicates that physiological stress was smaller when touching these materials. The lower minimum SBP in these three materials may be attributed to the relatively smaller increase in SBP by the contact (the lower maximum SBP), which also indicates lower physiological stress. On the other hand, the lowest maximum PR in aluminum can be a result of the physiological reflex to a larger increase in SBP and DBP when touching this material. To summarize, the changes in blood pressure and pulse rate simultaneously suggest that touching the wood, particularly Japanese cypress or uncoated Japanese oak induces less physiological stress than touching aluminum.

In the subjective ratings, wooden materials were rated to be significantly warmer compared to the non-wood materials, that is, aluminum and polyethylene, regardless of the species or surface coating, which corresponds to a smaller amount of heat transfer in the wooden materials. Moreover, the subjective comfort perception was generally higher when touching the wooden materials than when touching aluminum, except that the difference did not reach statistical significance in the case of the uncoated Japanese oak $(p=0.074)$. Compared to aluminum, polyethylene was evaluated to be more comfortable and almost as comfortable as the wooden specimens. The correlation analysis suggests that although perceived comfort partly relates to the amount of heat transfer or perceived warmth, it might be influenced by other factors. Such factors may include naturalness, smoothness, and dryness of the surface as suggested by previous studies $[18,19]$.

In this study, the effect of species on the amount of heat transfer was significant. This can be attributed to the lower thermal conductivity of the Japanese cypress than that of the Japanese oak, as heat flux is known to correlate with thermal conductivity positively [20], which is related to the density of wood [21]. Conversely, the effect 
of surface coating on the heat transfer was not significant. This may be because the layer thickness of the coating employed in this study was thin enough to neglect compared to the diameter of the grab bars. Therefore, the thermal properties of the coated specimens can be considered to be equal to that of the wood. Although not evident in the heat transfer, the surface coating slightly influenced the subjective ratings of both species. The perceived warmth of the unpainted Japanese cypress was rated highest, and only the unpainted cypress showed significant differences between the hardwood specimens. The coated oak was evaluated to be significantly more comfortable compared to the non-wooden bars, whereas the uncoated oak was not. These perceptions may be affected by thermal or other properties arising from the presence or absence of surface coating, which are not reflected in the amount of heat transfer.

The difference between the female and the male participants was significant in the score of subjective comfort and the maximum pulse rate: female participants generally gave higher comfort scores to all the materials and exhibited lower maximum pulse rate. Although not statistically significant, the $p$-values were relatively small in some of the hemoglobin indices. Therefore, gender differences in both physiological and psychological responses need to be carefully investigated in further studies, considering the fact that gender differences have been reported in both thermal perception $[22,23]$ and thermoregulation [24].

This study demonstrated that even a mild local cold could cause similar, although smaller, physiological changes that were previously shown by more severe cold exposures. Part of the physiological mechanisms underlying the observed response was speculated based on the correlation analysis among the physiological indices. However, as the correlation coefficients we obtained were relatively small, further investigations are required to understand the interactions among different physiological functions entirely. There should be other factors that affect physiological changes, including individual differences at various levels. More precise investigations with other related physiological indices such as peripheral (finger) blood flow and temperature, cardiac output, or sympathetic and parasympathetic nervous activities are needed.

The number of participants in this study was relatively larger than previous studies that dealt with physiological responses to various sensory simulations originating from wood. However, it still may not be sufficient to fully discuss the influence of gender and other individual differences. Since the development of measurement devices is rapidly progressing, physiological experiments may become more accessible and easier to implement in the future. Further studies can attempt to accumulate physiological and psychological data with a group of larger sample sizes and scrutinize the influence of gender, age, and other factors more precisely.

\section{Conclusions}

This study investigated the physiological responses, subjective perceptions, and magnitude of heat transfer during a short period of contact with wood and other materials in young participants. The heat transfer during the 90-s of contact was significantly lower with wood than with the non-wooden materials, such as aluminum and polyethylene. The warmth perception was generally higher in the wooden materials than in the non-wooden materials, and the perceived comfort was higher with the wooden materials than with the aluminum. The female participants generally gave higher comfort scores compared to the male participants.

We demonstrated that touching wood, i.e., Japanese cypress (both coated and uncoated) and Japanese oak (without surface coating) induced lower physiological stress compared to touching aluminum. This could be because of the smaller heat transfer resulting from lower thermal conductivity. This might be of importance when considering a long-term effect in cases such as touching handrails in cold hallways in daily life or stepping down from the bed and touching the cold floor with bare feet every morning.

\section{Abbreviations \\ SBP: Systolic blood pressure; DBP: Diastolic blood pressure; PR: Pulse rate; OXY: Oxygenated (oxy-)hemoglobin concentration; DEOXY: Deoxygenated (deoxy-)} hemoglobin concentration.

\section{Acknowledgements}

We thank Mr. Hironari Ohki and Mr. Ryoichi Hasegawa for their assistance in preparing and conducting the experiment. We also thank Dr. Keita Ishibashi for his valuable advice about interpreting the physiological data.

\section{Authors' contributions}

All authors contributed to the planning of the research protocol. YT and MS collected and analyzed the data. YT mainly prepared the article with major contributions from MS. All authors read and approved the final manuscript.

\section{Funding}

This study was supported by the Forestry and Forest Products Research Institute under Research Grant No. 201418.

\section{Availability of data and materials}

The datasets used and/or analyzed during this study are available from the corresponding author upon reasonable request.

\section{Declarations}

Competing interests

The authors declare that they have no competing interests. 


\section{Author details}

1 Department of Biomaterial Sciences, Graduate School of Agricultural and Life Sciences, The University of Tokyo, 1-1-1 Yayoi, Bunkyo-ku, Tokyo 113-8657, Japan. ${ }^{2}$ Department of Wood Properties and Processing, Forestry and Forest Products Research Institute, 1 Matsunosato, Tsukuba, Ibaraki 305-8687, Japan.

Received: 12 November 2020 Accepted: 17 March 2021

Published online: 31 March 2021

\section{References}

1. Sadoh T, Nakato K (1987) Surface properties of wood in physical and sensory aspects. Wood Sci Technol 21(2):111-120

2. Takemura T, Kurai T, Meda H (1988) Tactile roughness of planed wood in relation to its surface roughness and growth ring structure. J Soc Mater Sci Japan 416:544-548 (in Japanese with English abstract)

3. Okajima T, Takeda Y, Tanahashi I (1976) Tactile hardness of building materials. Trans Arch Institute Japan 246:1-5 (in Japanese with English abstract)

4. Morikawa T, Miyazaki Y, Kobayashi S (1998) Time-series variations of blood pressure due to contact with wood. J Wood Sci 44:495-497

5. Sakuragawa S, Kaneko T, Miyazaki Y (2008) Effects of contact with wood on blood pressure and subjective evaluation. J Wood Sci 54:107-113

6. Ikei H, Song C, Miyazaki Y (2018) Physiological effects of touching hinoki cypress (Chamaecyparis obtusa). J Wood Sci 64:226-236

7. Ikei H, Song C, Miyazaki Y (2017) Physiological effects of touching coated wood. Int J Environ Res Public Health 14(7):773

8. Daanen HAM (2003) Finger cold-induced vasodilation: a review. Eur J Appl Physiol 89:411-426

9. LeBlanc J, Côté J, Dulac S, Dulong-Turcot F (1978) Effects of age, sex, and physical fitness on responses to local cooling. J Appl Physiol Respir Environ Exerc Physiol 44(5):813-817

10. Sendowski I, Savourey G, Besnard Y, Bittel J (1997) Cold induced vasodilatation and cardiovascular responses in humans during cold water immersion of various upper limb areas. Eur J Appl Physiol Occup Physiol 75(6):471-477

11. Korhonen I (2006) Blood pressure and heart rate responses in men exposed to arm and leg cold pressor tests and whole-body cold exposure. Int J Circumpolar Health 65(2):178-184

12. Ikäheimo TM (2018) Cardiovascular diseases, cold exposure and exercise Temperature (Austin) 5(2):123-146
13. Cui J, Wilson TE, Crandall CG (2002) Baroreflex modulation of muscle sympathetic nerve activity during cold pressor test in humans. Am J Physiol Heart Circ Physiol 282(5):H1717-H1723

14. Hoshi Y, Kobayashi N, Tamura M (2001) Interpretation of near-infrared spectroscopy signals: a study with a newly developed perfused rat brain model. J Appl Physiol 90(5):1657-1662

15. Paulson OB, Strandgaard S, Edvinsson L (1990) Cerebral autoregulation. Cerebrovasc Brain Metab Rev 2(2):161-192

16. Hamner JW, Cohen MA, Mukai S, Lipsitz LA, Taylor JA (2004) Spectral indices of human cerebral blood flow control: responses to augmented blood pressure oscillations. J Physiol 559:965-973

17. Hamner JW, Ishibashi K, Tan CO (2019) Revisiting human cerebral blood flow responses to augmented blood pressure oscillations. J Physiol 597(6):1553-1564

18. Bhatta SR, Tiippana K, Vahtikari K, Hughes M, Kyttä M (2017) Sensory and emotional perception of wooden surfaces through fingertip touch. Front Psychol 8:367

19. Ohkoshi M, Yamazaki S, Noguchi K, Furuta Y, Fujiwara Y (2011) The difference of tactile sensations of coated oak wood between elderly person and young person. J Soc Mater Sci Japan 60(4):293-299 (in Japanese with English abstract)

20. Harada Y, Nakato K, Sadoh T (1983) Thermal properties and sensory warmth of wood surfaces. Mokuzai Gakkaishi 29(3):205-212 (in Japanese with English abstract)

21. Kollmann FFP, Cote WA Jr (1968) Physics of wood. In: Kollmann FFP, Cote WA Jr Principles of wood science and technology, I Solid wood, SpringerVerlag Berlin Heidelberg

22. Averbeck B, Seitz L, Kolb FP, Kutz DF (2017) Sex differences in thermal detection and thermal pain threshold and the thermal grill illusion: a psychophysical study in young volunteers. Biol Sex Differ 8:29

23. Kaikaew K, van den Beukel JC, Negger SJCMM, Themmen APN, Visser JA, Aldo $\mathrm{G}$ (2018) Sex difference in cold perception and shivering onset upon gradual cold exposure. J Therm Biol 77:137-144

24. Iyoho $A E, \mathrm{Ng} L$, MacFadden $L$ (2017) Modeling of gender differences in thermoregulation. Mil Med 182(S1):295-303

\section{Publisher's Note}

Springer Nature remains neutral with regard to jurisdictional claims in published maps and institutional affiliations.

\section{Submit your manuscript to a SpringerOpen ${ }^{\circ}$ journal and benefit from:}

- Convenient online submission

- Rigorous peer review

- Open access: articles freely available online

- High visibility within the field

- Retaining the copyright to your article

Submit your next manuscript at springeropen.com 